\title{
The Impact of E-Commerce Development on Urban Logistics Sustainability
}

\author{
Dustin Schöder, Feng Ding, Juliana Kucht Campos \\ Technische Universität Berlin, Straße des 17. Juni 135, 10623 Berlin, Germany \\ Email: schoeder@logistik.tu-berlin.de,fengding@logistik.tu-berlin.de,campos@logistik.tu-berlin.de
}

Received 16 February 2016; accepted 26 February 2016; published 1 March 2016

\begin{abstract}
The purpose of the present paper is to present some sustainable solutions for urban logistics. The approach is to identify the present challenges for urban logistics caused by the increase of freight volumes due to the development of e-commerce. To meet them, companies' sustainable practices were analyzed and the utilization of new electric power train technologies seem to offer interesting results for reducing carbon emission impacts. Using methods of literature review and experiences from ongoing electric mobile research projects, this paper argues that electric vehicles in urban distribution are a yet underestimated element towards more efficient transport processes-hence economic advantages for companies, towards the reduction of a company's footprint and even towards an increased service level for the customers.
\end{abstract}

\section{Keywords}

\section{E-Commerce, Urban Logistics, Sustainability, Best Practices, Electric Vehicles}

\section{Introduction}

Sustainable urban logistics has received much attention in recent years, due to continuously increasing freight volumes in e-commerce. Online shopping is a modern retail channel which, in alignment with the global trend of urbanization, leads to increased commercial traffic, congestions and hence pollution in areas with dense population. Many companies already introduce sustainable initiatives in order to reduce their ecological footprint both in terms of sustainable production and sustainable distribution. Simultaneously new electric power trains in vehicles provide an opportunity towards emission free transport. However, this new technology is mostly not considered within companies' sustainable initiatives, yet.

The present paper presents key challenges of e-commerce and an approach towards sustainable urban logistics by using electric vehicles and by further integration of all participants within the transport chain, which corresponds with companies' sustainable initiatives.

\section{E-Commerce and Its Challenges}

E-commerce currently appears to be one of the fastest growing marketing channels for different kinds of products and services for consumers. Buyers and sellers that engage in E-commerce retail trade are no longer re- 
stricted by store hours, geographic marketing areas, or catalog mailing lists. In Figure 1, it is expected that the global B2C e-commerce trades are going to reach the value of 2.356 trillion dollars and the percentage of the global GDP account for 1.61\% in the year 2018, almost nearly twice with year 2013. According to the eMarketer's forecast, Asia-Pacific, which just about $16 \%$ of the total population but account for as many as $46 \%$ of all digital buyers in the world, is now expected to become the leading region for e-commerce sales in 2015, representing a 33.4\% share next year, compared to 31.7\% in North America and 24.6\% Western Europe (Figure 2).

Furthermore, due to the development of communication technology, mobile e-commerce and social media will rapidly gain in importance. Mobile traffic to e-commerce sites has increased from $3 \%$ to nearly $37 \%$ in the last four years. Social media is evolving in much the same way, in $2015,5 \%$ of all online retail revenue is forecasted to be attributable to social media, representing a sizeable $\$ 14$ billion [1]. Moreover, cross-border online shopping is worth $\$ 105$ billion in 2013 with 94 million consumers regularly buying from overseas websites. By 2018, this will increase nearly 200\% to $\$ 307$ billion with 130 million cross-border online shoppers [2].

The reasons for the stated developments in online shopping are better prices, larger selection, convenience, and time savings [3]. However, because the online products is likely to be packaged individually and hard to return them, a further increase of internet shopping will lead to more deliveries and an increasing freight volume in residential area. It may have some negative effects like congestion issues, environmental concern and traffic safety etc. To solve this problem, sustainable urban logistics solutions are required in the city centers [4].

Distinct from offline business models, e-commerce is characterized by higher interactivity, 24/7 availability and hence an increased importance of logistics processes. The logistical systems of many companies are not sufficient to manage the new challenges.

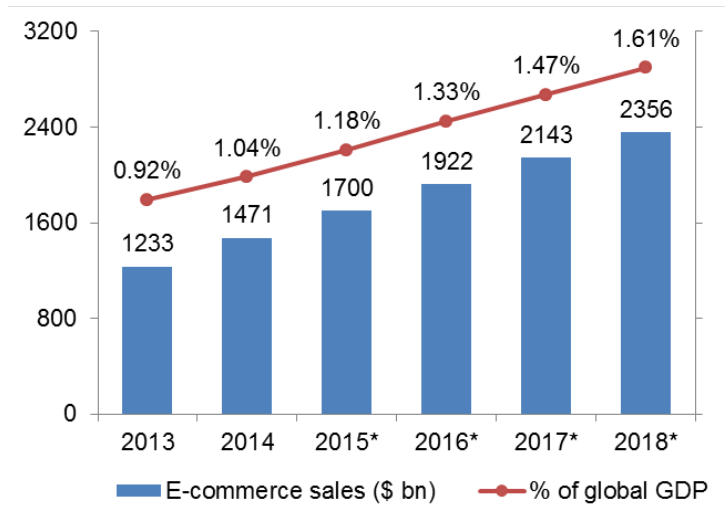

Figure 1. Global B2C E-commerce sales and percentage of GDP from 2013 to 2018 (in billion U.S. dollars) [1].

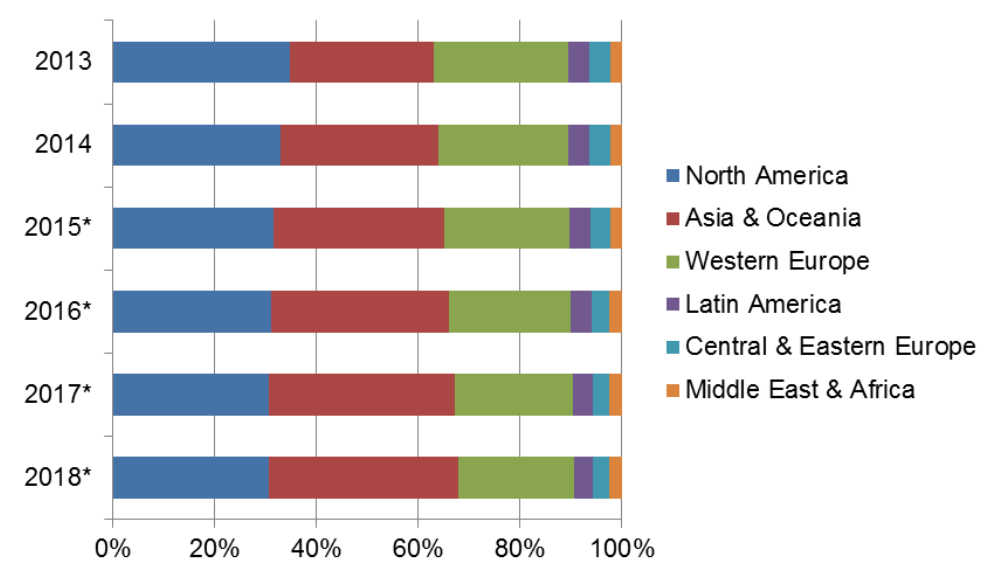

Figure 2. B2C E-commerce sales share worldwide, by region, from 2013 to 2018 [1]. 
1) Fast and flexible deliveries: A positive delivery (or return) experience is essential in order to create customers loyalty to e-retailers. Concerns with delivery remain a barrier for consumers shopping online for physical goods, specifically when looking to shop cross-border. In addition, flexibility in delivery location and flexibility in delivery time slots are becoming increasingly relevant to consumers. Furthermore, tends to favor faster transportation modes can increase fuel consumption exponentially and may lead to inefficient utilized transport capacities.

2) Home delivery: The most important consequence of e-commerce is the changed sink of transport chains. Highly bundled shipments to retailers are substituted with far less bundled shipments to end consumers. Therefore, retailer and manufacturer will have to reconfigure their established logistics systems from consolidated shipments to small packages. This development is often criticized for causing increased traffic.

3) Reverse logistics: The increasing challenge in reverse logistics today is the growth of returns resulting from the rise of e-commerce. In most countries, more than half of all online shoppers have returned an online purchase. The highest incidence is in Germany where $77 \%$ of online shoppers have made a return. The high return rate in Germany is favored by the fact that most returns are free of charge, especially in the fashion segment. As a result, e-commerce development cannot ignore efficient operations of reverse logistics [5].

The global trend of urbanization is aggravating the challenges in e-commerce. Due to the increased freight volumes, the majority of all sinks in e-commerce caused transport chains is located in urban areas. Smaller lot sizes and increased freight volumes are increasingly causing congestions and pollution in areas with dense population. Therefore, the general public demands to restrict the urban access of freight vehicles, resulting in a bottleneck for the further development of e-commerce. The logistics need a sustainable solution.

\section{Sustainable Supply Chain Practices}

Using the Framework for Managing Sustainable Supply Chain Practices [6] as a background, data from six companies were collected in order to better understand which strategies and practices have been implemented to overcome the sustainability challenges into their logistics processes caused by e-commerce operations (Table 1). The selected companies are included either in the Newsweek Green Ranking or in the Global Social Ranking, representing, thus benchmarks of the consumer goods industry. Information about companies' practices towards a more sustainable supply chain was searched in their website as well as available free self-publications [7].

The findings provided some interesting insights about the current behavior of companies from consumer goods industry, especially the lack of certain investments that might result in more sustainable operations when considering the challenges intensified by e-commerce. The first finding was a lack of collaborative initiatives with suppliers, despite the fact that the selected companies invest significantly in supplier selection and assessment practices such as requiring them to comply with specific sustainability guidelines. Some changes were visible such as the use of "nearshoring" or "backshoring" which means to return operations to their home country or closer to home [8]. This strategy helps reducing costs and overall emissions from inbound transport. Furthermore, practices related to the governance were vast. All companies have clear environmental and social standards such as code of conduct, and manage sustainability though specific departments or cross functional committees. The investments in employees' training, reward systems according to their results and social corporate benefits were extensively reported. Most of the companies are internationally certified which might require

Table 1. Researched companies.

\begin{tabular}{|c|c|c|c|}
\hline Company & Headquarter & Main products & Main documents used \\
\hline Adidas & Germany & Sportswear & $\begin{array}{l}\text { Sustainability Progress Report } 2013 \text {, } \\
\text { Health \& Safety Guidelines 2010, } \\
\text { Guide to best environmental practices } 2005\end{array}$ \\
\hline Beiersdorf & Germany & Cosmetics & Sustainability Review 2012 \\
\hline Bayer & Germany & Medicines & Integrated Annual Report 2014 \\
\hline Henkel & Germany & Cleaning and beauty care products & Sustainability Report 2014 \\
\hline Natura & Brazil & Cosmetics & $\begin{array}{l}\text { Natura annual report 2013, } \\
\text { Annual Report } 2011\end{array}$ \\
\hline BRF-Brasil Foods & Brazil & Food and beverage & Annual Sustainability Report 2014 \\
\hline
\end{tabular}


the establishment of measurement systems capable to measure risk and safety, as well as control the KPIs and internal improvement targets. As operations are enlarged due to e-commerce trade, customers are demanding more transparency in companies' operations. A well established, corporate governance system help firms to standardize procedures, increase control and therefore meet the demands.

Procurement initiatives focus on obtaining sustainable materials and packaging, specially recycled and reusable ones. Some countries require packaging to be designed for recovery and reuse, with a minimum recyclable rate. Others entirely ban or restrict certain materials, such as United States and South Korea. Regarding production management, all companies are investing in developing more sustainable solutions. However, they seem not to invest in involving customers during this process. Efforts to reduce overall consumption, including energy and water, as well as attempts to use of alternative energy sources were cited by the researched firms. Lastly, after products are ready to be delivered, it was clear that these benchmarks from consumer goods industry are not considering the distribution process and even less the last mile as an opportunity for reducing costs, emissions and improving supply chain sustainability. Initiatives related to network design; transport modes, equipment, vehicles and overall distribution processes were considerably few. Except for investments in greener constructions, none of the selected companies seems to be involved in processes that are mostly outsourced for logistics service providers (LSPs). Beiersdorf was the only company that published some efforts to optimize container loading, truck capacity utilization and transport routes. According to the company's website, since June 2012 truck utilization has dropped by $27 \%$ and $\mathrm{CO}_{2}$ emissions by $32 \%$. The company seems to be one step ahead the others as it uses the collaborative platform together with some carriers for reporting $\mathrm{CO}_{2}$ emissions and standards for the monitoring process.

As described previously, e-commerce is requiring companies to deliver products faster and closer to the customers, in other words, in urban centers. Changes towards less pollutant modes or vehicles could be supported and encouraged by manufacturers, through a combined investment and benefits sharing culture. In an attempt to improve network and processes optimization, collaborative approaches may improve simultaneously service quality and profit to all members. The reverse logistics problem, intensified by e-commerce, may be also solved with alternative solutions which may not require governmental strict changes in regulations.

\section{Urban Logistics and Electric Vehicles}

The recent technological developments in electrifying automotive power trains are largely caused in political decisions to reduce GHG-emissions caused by traffic. Currently, 18\% of global GHG-emissions are caused by the transport sector [9]. Pollution, especially in urban areas, is becoming a global challenge and is increasingly affecting the quality of life - the so called urban wellbeing-by urban residents. The e-commerce caused challenges of increased freight volumes, reduced lot sizes and an increased number of delivery points (e.g. households) can be overcome by a transport technology with zero (local) emissions. Various research projects have shown that the electrification of last-mile distribution is possible and has the potential to reduce costs of distribution [10]-[13]. In combination with modern telematics technologies and an integration of those with order management and vehicle routing systems, the positive effects of electric vehicles (EV's) have proven to increase dramatically [13]. This approach of an integrated, smart last-mile distribution results in a triple-win situation. At first, an improved service level for customers can be realized, trough more flexibility in terms of delivery location and time slots enabled by dynamic vehicle routing and improved communication with the customers. Secondly, electrified urban distribution is characterized by reduced vehicle operating costs, due to reduced maintenance and fuel costs. In fact, an increased utilization of EV's leads to further savings in regard to transport costs per delivery. The third positive effect of electrified urban distribution is the already mentioned zero emission transport, especially in combination with dynamic vehicle routing which takes current congestions and traffic situations into account. A further potential of electrified urban distribution is risk reduction for the transport executing company by ensuring unlimited future access to inner city areas, despite increasing governmental initiatives to restrict access to city centers for vehicles with internal combustion engines. In addition, companies with a strong strategic focus on sustainable products are regarding EV and sustainable distribution as a unique selling proposition in the market. This development is likely to continue, especially in regard to the LOHAS (lifestyle of health and sustainability) trend in (yet mostly western) customers attitudes [14].

Various research projects have shown that the application of EV's in distribution can cause a cascade of positive effects, but also allows restructuring entire distribution systems in B2B deliveries of consumer goods. 
Night-time delivery of stores for instance, could reduce rush hour congestions in commercial transport because of the reduced noise of EV's. In regard to the reduced operation costs of EV's, new business models-e.g. in the CEP (courier, express, parcel) sector—with multi shift operations are possible. Despite all positive effects and potential new business opportunities, the implementation of an electrified urban distribution is a challenge for companies. Even considering future improvements in electric power trains and the possible utilization of EV's in medium range distribution, the initial investments for companies into the needed infrastructure for EV will stay a hurdle. Conventional distribution with internal combustion engine powered vehicles currently possesses a system lock-in effect, which is even strengthening the hurdle. Latest experiences have shown that investments in charging infrastructure, EV's and modern disposition tools are rather high, due to the current market prices of the mentioned items [11] [13]. But pioneer companies, such as DHL and UPS, who did these investments in electrified distribution start experiencing the above explained benefits and state, that overcoming the system lock-in effect was worth the effort.

\section{Conclusion}

In recent years, e-commerce development has changed the retail sector. The increasing importance of this distribution channel leads to increased freight volumes - especially in urban areas-, hence to increased traffic and pollution within these areas. At the same time, sustainability is becoming increasingly important for the customer. Due to the growing environmental awareness in the society, companies are adopting this awareness by starting sustainable initiatives in order to measure and reduce their ecological footprint and to meet customers demand. Analysis have shown that most companies focus on internal process development and resource utilization in order to meet their sustainability goals, but a holistic and supply chain wide approach which includes suppliers as well as the distribution to the customer, is still rare. The utilization of new power train technologies and the integration of all supply chain participants by collaborative initiatives are two powerful levers to face the challenges of e-commerce in urban areas. Despite rather high initial investments in electric vehicles and the related infrastructure, this technology opens further possibilities towards a zero emission distribution in urban areas, hence meets the demand of the customers for faster and more sustainable transport. In addition, the reduction of transport related emissions is about to become a key element of companies' sustainable objectives. Furthermore, a keen interlink between all participants of a supply chain as well as an integrated approach in fleet management and vehicle routing have the potential for more efficient logistics processes. The mentioned holistic sustainable approach will result in economic advantages for companies, ecological advantages by a reduction of traffic volume and advantages for the customer by an improved service level.

\section{References}

[1] Tradeglobal (2015) Bridging the Gap between Social Media and E-Commerce. http://www.tradeglobal.com/bridging-gap-social-media-ecommerce/

[2] Paypal (2013) Modern Spice Routes-The Cultural Impact and Economic Opportunity of Cross-Border Shopping. https://www.paypal-media.com/assets/pdf/fact_sheet/PayPal_ModernSpiceRoutes_Report_Final.pdf

[3] Hays, T., Keskinocak, P. and de López, V.M. (2004) Strategies and Challenges of Internet Grocery Retailing Logistics. Applications of Supply Chain Management and E-Commerce Research, 92, 217-252. http://dx.doi.org/10.1007/0-387-23392-X_8

[4] Russo, F. and Comi, A. (2010) A Classification of City Logistics Measures and Connected Impacts. Procardia-Social and Behavioral Sciences, 2, 6355-6365. http://dx.doi.org/10. 1016/j.sbspro.2010.04.044.

[5] Eleonora, M., Saskia, S., Corinne, B., Laetitia, D. and Barbara, L. (2014) The Impact of E-Commerce on Final Deliveries: Alternative Parcel Delivery Services in France and Germany. Transportation Research Procedia, 4, 178-190. http://dx.doi.org/10.1016/j.trpro.2014.11.014

[6] Campos, J.K. (2015) Integrated Framework for Managing Sustainable Supply Chain Practices, Schriftenr. Univ.-Verl. der TU Berlin, Berlin.

[7] Bowers, T. (2010) From Image to Economic Value: A Genre Analysis of Sustainability Reporting. Corporate Communications: An International Journal, 15, 249-262. http://dx.doi.org/10.1108/13563281011068113

[8] Goel, A., Moussavi, N. and Srivatsan, V.N. (2008) Time to Rethink Offshoring. McKinsey Quarterly, 14, 1-5.

[9] World Economic Forum (2009) Supply Chain Decarbonization-The Role of Logistics and Transport in Reducing Supply Chain Carbon Emissions, Geneva. 
[10] TUB Logistics Institute (2015) Smart E-User.

https://www.logistik.tu-berlin.de/menue/forschung/aktuelle_forschungsprojekte/smart_e-user/

[11] DLR (2015) DisLog. http://www.dlr.de/vf/desktopdefault.aspx/tabid-2974/1445_read-39902/

[12] Kvechain (2015) KV E-Chain. http://kvechain.de/kvechain/

[13] Hacker, et al. (2015) Wirtschaftlichkeit von Elektrofahrzeugen in Gewerblichen Anwendungen-Abschlussbericht, Berlin.

[14] Häusler, R. and Kerns, C. (2008) LOHAS—Mythos und Wirklichkeit, Berlin. 